\title{
Biosynthesis and Potential Screening of Butyrate Type of Polymer Obtained from Bacillus Megaterium
}

\author{
Akshay Jirage ${ }^{1}$, Khyaam Shaikh ${ }^{1}$, Kate Vaishali ${ }^{1}$ and Payghan Santosh ${ }^{1,2 *}$ \\ ${ }^{1}$ Department of Pharmaceutics, Tatyasaheb Kore College of Pharmacy, India \\ ${ }^{2}$ Shivaji University, India
}

Submission: October 02, 2017; Published: November 27, 2017

*Corresponding author: Santosh Ambadas Payghan, Department of Pharmaceutics, Tatyasaheb Kore college of Pharmacy, Warananagar, Panhala, Kolhapur-416113, MS, India, Tel: +919096202858; Email: sapayghan.tkcp@gmail.com

Abstract

Diverse Bacillus strains are known as producers of polyhydroxyalkanoates (PHAs) under nutrient-limiting conditions. However, these limiting conditions have the same nutritional characteristics that stimulate spore generation in Gram-positive microorganisms. In the present work a new isolated Bacillus megaterium strain was characterized and studied in terms of its ability for producing polyhydroxybutyrate (PHB) by implementing different fermentation configurations on formulated media. The isolated strain was able to produce PHB up to 41 and $55 \%$ of its dry cell weight during bioreactor experiments employing glucose and glycerol as carbon source, respectively. The produced biopolymer was characterized and identified by using Fourier transform infrared (FTIR) techniques. PHB was effectively screened from prime PHB producer Bacillus megaterium yielded highest polymer production $41 \% \mathrm{w} / \mathrm{w}$ by using cheap C and $\mathrm{N}$ sources at 35 and $4 \mathrm{~g} / \mathrm{L}$ employed concentration for molasses and ammonium chloride respectively. The morphological tests, phisio-chemical assessment and characterizations of finished polymer substance were carried out. PHB shows viscosity 0.7993 (Pas), sharp peak arouse at $176.12{ }^{\circ} \mathrm{C}$ in DSC analysis, $235.8 \mathrm{~nm}$ $\lambda \max$, Successive FTIR analysis, EDS and Microscopic imaging analysis (SEM) were performed to get satisfactory reasoning for confirmation

Keywords: Poly- $\beta$-hydroxybutyrate (PHB) production and characterization; Bacillus megaterium; Bioprocessing techniques

\section{Introduction}

Bio-based polymers are materials which are produced from renewable resources. The terms bio-based polymers and biodegradable polymers are used comprehensively in the literature, but there is a key difference between the two types of polymers [1]. Biodegradable polymers are seen as the budding solution to manage problems concerning worldwide environmental and solid waste management. These biodegradable plastic materials can retain the desired material properties of conformist synthetic plastics, and can be completely degraded without parting any undesirable rest [1,2]. With the aim of substituting the functionality of plastics of petrochemical source, as well as mounting the range of application of bioplastics to a extensive range, polyhydroxyalkanoates (PHAs) are supposed as the most suitable materials because of their adaptability in terms of physical properties and chemical characteristics [2] Polyhydroxybutyrate (PHB) is the most widely studied member of the PHA family and the first one that has been produced at industrialized scale. It has been used, among other applications, to produce bottles, films and fibers for biodegradable wrapping materials and as mulch films for agriculture [3]. However, applications of PHB are not restricted to these areas, and they have been extensive to osteosynthetic resources, bone plates, surgical sutures, rivets, tacks, and many other materials in medicine [4]. At industrial level, PHB is commonly produced from cupriavidus necator (Alcaligenes eutrophus) and Alcaligenes latus (Azohydromonas lata). These microbes can accrue PHB up to $80 \%$ of the dry cell weight. PHB produced from these Gram-negative organisms is employed in a wide variety of products [5]. However, for its use in the area of biomedicine, an extra separation stage should be carried out since Gram negative organisms contain end toxins in the outer membrane lip polysaccharide. The viability of microbial large scale production of PHB is dependent on the development of a low cost method that produces biodegradable plastics with properties similar or better to petrochemical plastics. The commercial production of PHB has been using relatively economical substrates such as methanol, beet molasses, ethanol, starch and whey, cane molasses as a sole carbon source [6]. However, unrefined carbon sources such as corn syrup, cane molasses, beet molasses, or 
malt extract, also support PHB formation, obtaining yields of PHB comparable to, even better than the refined sugars. Beet molasses and malt extract promoted higher polymer production per liter due to a growth stimulatory effect. The metabolic pathway of PHB involved the regulation of its synthesis in the microbial cells. The microorganism and the strategy of production were affected on duration of fermentation, growth rate, carbon source concentration, etc [7].

Synthetic Polymer may produce hazardous problem during formulation that produce the bioaccumulation in the body. This accumulated trace of polymer creates health related problems. PHB are found functionally more and can be better for use in pharmaceutical formulations. This will help to improve pharmaceutical drug delivery of different therapeutic agent. This biopolymer is effective tool to control or extend the drug release rate of pharmaceutical formulation [8].

The current study was based on screening of biopolymer which would satisfy the rising demand of sustainable economic biopolymer production from bacterial genera. Screened Poly$\beta$-hydroxybutyrate (PHB) has found to be an optimistic role in biomedical applications and pharmaceutical drug delivery scenario. The variety of (semi) synthetic polymer available in market and these many synthetic polymers are being used now a days in drug delivery systems synthetic polymers have certain disadvantages such as their high production cost, nonbiodegradability, toxicity and so it proven their impact on probability of bioaccumulation $[9,10]$. Such accumulation for long time hampers the human health. Hence these demerits avoided by application of screened biopolymer candidate PHB as drug release retardant tool. Bacillus megaterium grows in minimal medium without any added growth factors. Indeed, the ability of B. megaterium to accumulate PHB is so dominant that the PHB content in the cells could reach up to $42 \%$ of the cell dry weight [11].

This work, in order to study the effect of the molasses in the medium on Bacillus megaterium growth and PHB accumulation and productivity were estimated by the time during growth. The evaluation of the PHB production as a low cost process affects the properties of the biopolymer synthesized by this bacterium, the chemical structure (Fourier transform infrared) and the thermal properties of polyhydroxybutyrate (PHB) obtained from this fermentation were determined. PHB was effectively screened from prime PHB producer Bacillus megaterium yielded highest polymer production using cheap $\mathrm{C}$ and $\mathrm{N}$ sources for molasses and ammonium chloride respectively. The morphological tests, phisio-chemical assessment and characterizations viz; Rheology, DSC analysis, EDS and Microscopic imaging analysis (SEM) were performed to get satisfactory reasoning for confirmation of finished polymer substance.

\section{Materials and Methods}

Bacterial fermentation was carried out using Bacillus megaterium ATCC 6748. A lyophilized culture was reactivated at $30{ }^{\circ} \mathrm{C}$ for $24 \mathrm{~h}$ in a growth medium as Nutrient agar medium containing Nutrient Agar(NA)3.5\%, Peptone 2.5\%, NaCl 0.5\%, Yeast $0.1 \%$, Beef extract $0.5 \%$, Agar powder 3\% and Distilled water. The nutrient components as sugar, nitrogen, phosphate and trace elements were sterilized separately at $121{ }^{\circ} \mathrm{C}$ for $20 \mathrm{~min}$.

\section{Screening and characterization of biopolymer from microbial source}

Primary screening of microbial source: Collection of soil samples. Soil samples were collected near from Biotechnology department TKIET campus, Warananagar. It were collected apart from 3-4cm deep from surface was used for isolation of the bacteria. It were kept in plastic bags and marked with collection details and remained protected from the light and used for further study [12].

Isolation and purification of bacterial strains. The collected soil samples screening to obtain spore forming bacteria was performed by heating sample at $80{ }^{\circ} \mathrm{C}$ for $10 \mathrm{~min}$. Samples were prepared by using sterile distilled water. Soil sample supernatants were subjected to serial diluted $10^{-1}, 10^{-2}, 10^{-3}, 10^{-4}$ and $10^{-5} .0 .2 \mathrm{ml}$ of diluted soil samples were plated on nutrient agar (NA) plates [12].

Media preparation and sterilization. Composite media ingredients were taken in flask. The above media was sterilize for $121^{\circ} \mathrm{C}, 15 \mathrm{lb}$, for 15 minutes and allow cooling it after media was kept in pre-sterilized laminar air flow in between two Bunsen burner to avoid cross contamination. Aseptically transferred the media into sterilized Petri plate and allowed to cool for $15 \mathrm{~min}$ and after that a desired culture transplant was used for further study. The stationary phase media plates were incubated at $30{ }^{\circ} \mathrm{C}$ for 48 hours [12]. Effect of pH on PHB production.

Different initial pH of the medium (6.0 to 8.0) was used to check whether $\mathrm{pH}$ has any noticeable effect on PHB production. The initial $\mathrm{pH}$ of the medium was adjusted by $1 \mathrm{~N}$ Hydrochloric acid or Sodium hydroxide [12].

Screening of PHB producing bacterial strains: Sudan Black B Staining technique. Well isolated, morphologically distinct colonies were sub cultured on nutrient agar plates and were subsequently stained with Sudan Black B (0.3\% in 96\% ethanol). Colonies stained with Sudan black B were selected as a positive for PHB production. The Sudan Black B positive isolates were further confirmed by Nile blue viable colony staining; where in $0.5 \mu \mathrm{g} / \mathrm{ml}$ Nile blue dye solution in alcohol (final concentration) was added to the sterilized media $[13,14]$. The selected PHA producing isolates were also analyzed for their gram nature.

Nile blue staining technique. Heat-fixed cells were treated with $1 \%$ Nile blue A for $10 \mathrm{~min}$ and the excitation wavelength of $460 \mathrm{~nm}$ selected and excitation was observed. Glycogen and polyphosphate did not stain. Nile blue A stain appeared to be a more specific stain for poly- $\beta$ - hydroxybutyrate than Sudan black B. 
Volutin Granule staining technique. Every Micro-organism has special characteristics these organisms store reserve food material in the form of granule. This reserve food granule is called as Volutin granule. To stain volutin granule Albert's staining method was employed. This technique evaluated for presence of granular lipid constituent like PHB in intracellular region of bacterial strains. In above staining methods, bacterial colonies positive for PHB production were selected by observing the granules under fluorescence microscope $[13,14]$ OLYMPUS Reflected Fluorescence System, (Olympus Corporation, Japan) using BXRFA fluorescence illuminator, fitted with Image Analyzer. After staining confirmation isolates were selected further studies. Stained isolate images for Nile blue and Volutin granule staining are illustrated in Figure $1 \& 2$ respectively.

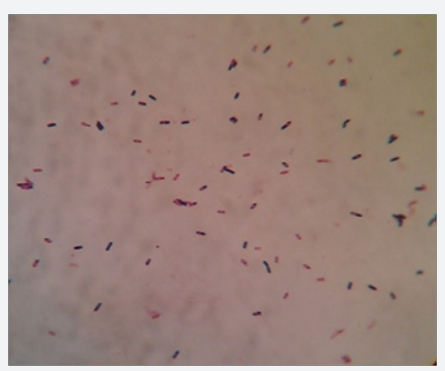

Figure 1: Nile blue staining microscopic view of Bacillus megaterium.

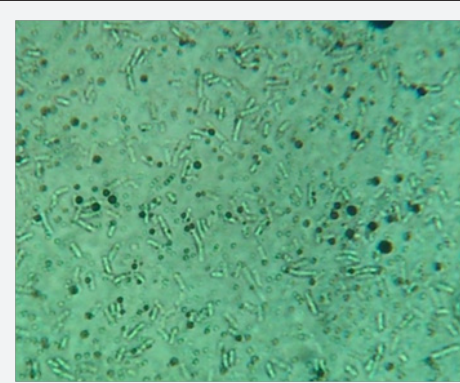

Figure 2: Volutin granule staining microscopic view.

Morphological characterization of microbial source: Colony characterization. The colony characters viz, Size, shape, Margin, Elevation, opacity and colour were observed on agar medium [15].

Cultivation of selected isolates and Standard PHB producer on media. Selected six isolates and the standard organism; Bacillus megaterium were inoculated separately onto nutrient agar plates and nutrient broth. The plates and broth were incubated at $30 \mathrm{oC}$ for 48 hours [15].

Harvesting of cell mass. Cell mass from agar plates was scrapped with the help of spatula and that from broth $5 \mathrm{ml}$ of $48 \mathrm{~h}$ at $30^{\circ} \mathrm{C}$ individual grown isolate was centrifuged at $6000 \mathrm{rpm}$ for broth culture and $4000 \mathrm{rpm}$ for solid state agar medium at $10^{\circ} \mathrm{C}$; centrifugation time $15 \mathrm{~min}$ was employed for both medium, these process was carried out in cooling centrifuge (Remi, Mumbai). Then obtained cell pellets was suspended in deionised water. The pellet of cell mass allow to air dry and after that placed in pre-weighed petri plates dried to a constant weight at $60{ }^{\circ} \mathrm{C}$ $[15,16]$. The plates were weighed again and dry cell weight of each isolate was calculated.

Production of biopolymer: PHB recovery. In the PHB recovery process was done by using two steps such as cell lysis and solvent extraction [17].

Cell lysis: The cell mass pellet were treated with Sodium hypochlorite $(10 \mathrm{~mL} / 50 \mathrm{~mL}$ culture pellets) and incubated at $30{ }^{\circ} \mathrm{C}$ for $2 \mathrm{~h}$. Sodium hypochlorite could not release all of the available protein, further treatment became necessary; which was subjected to homogenize by the homogenizer for $10 \mathrm{~min}$. which was subjected homogenized cell mass further treated by passing the ultrasonic waves by immersing probe sonicator's rod in cell mass pellet to attain firm cell lysis process [17].

Solvent extraction technique: PHB granules were extracted using chloroform extraction method. The above cell mass centrifuged at $6000 \mathrm{rpm}$ for $15 \mathrm{~min}$ supernatant was collected and filtered through whatman No. 1 filter paper and the non-PHB cell mass (NPCM) discarded. Obtained cell mass pellet suspension treated with chloroform at $45{ }^{\circ} \mathrm{C}$ with constant shaking on rotary shaker for 24 hours. PHB from chloroform phase was recovered by non solvent precipitation method comprising $(7: 3 \mathrm{v} / \mathrm{v})$ methanol and water. Followed by chloroform saturated cell mass suspension was poured into separating funnel; allowed to stand for separation, further that saturated chloroform layer was collected and kept at room temperature until PHB crystals emerge out [17].

\section{Characterization of PHB biopolymer}

Physiochemical characterization. The polymer samples were evaluated for its colour, odour and appearance.

Melting point determination: The melting point of $\mathrm{PHB}$ biopolymer was determined. Small amount of PHB sample was introduced into capillary tube attached to graduated thermometer and constant heat was supplied to Thile's tube containing paraffin oil assembly suspended in the bath [18]. The temperature at which polymer just melted was recorded.

Solubility determination. Solubility of polymer sample was determined by adding excess amount of polymer into solvent system ranging from polar to non-polar ones. These solvents allow to keep at room temperature for $24 \mathrm{hrs}$ with occasional shaking on rotary shaker [18].

\section{Rheological characterization}

Viscosity determination. The shear viscosity is defined as the ratio of shear stress to the shear rate under test conditions. Viscosity test was performed by using Brookfield R/S-CPS+ Rheometer. Measurements were carried out by using plate-plate type instrument and by using C75-2 spindle at $32 \pm 2{ }^{\circ} \mathrm{C}$. A gap of $0.5 \mathrm{~mm}$ was kept between two plates [19]. The viscosity of PHB sample was loaded between two plates and viscosity was recorded. 


\section{Spectral characterization}

Ultraviolet (UV) spectrum. Determination of the ultraviolet absorption maxima was recorded by convenient spectrophotometrically analysis of bacterial PHB has been devise. Quantitative conversion of poly- $\beta$-hydroxybutyric acid to colonic acid by heating in concentrated sulphuric acid and to found out scanning range of PHB. A standard curve was established with PHB conc. ranging from $2-10 \mu \mathrm{g} / \mathrm{ml}$. Solution of higher concentration of the screened PHB [20] was kept as standard and read with sulphuric acid as blank in the range of wavelength from 200-400nm using UV spectrophotometer (UV 1800, Shimadzu).

Fourier transforms infrared (FT-IR) spectroscopy. PHB was characterized by FTIR spectroscopy. The spectrum was recorded using FTIR Spectrophotometer (Agilent ATR CARY 630). The system employs a diamond ATR element that made proper contact between sample for evaluation without scratching of the window and sample analysis was done feasibly [21]. The scanning range was 3800 to $800 \mathrm{~cm}-1$.

Energy Dispersive X-ray Spectrometry (EDS)/Elemental Analysis. Energy Dispersive X ray Spectrometry (EDS) system that detects the x-rays emitted from a sample during electron imaging. The system consists of three main components: an $\mathrm{x}$-ray detector, separated from the SEM chamber by a very thin polymer window; pulse processing circuitry, which determines the energy of the detected x-rays; and analyzer equipment, Primary electrons can be backscattered which produces images with a high degree of atomic number $(Z)$ contrast. This interprets the x-ray data and displayed it on a computer screen [22]. The assignments for ED's multi-component quantification for four PHB crystals were represented in Table 9.

Thermal characterization (DSC). The DSC study was carried out on PHB to confirm its thermal properties and purity. The DSC patterns were recorded on a METTLER TOLEDO STARe System. $2 \mathrm{mg}$ of polymer was heated in crimped aluminium pans at a scanning rate of $20^{\circ} \mathrm{C} / \mathrm{min}$ in an atmosphere of nitrogen gas flow $40 \mathrm{ml} / \mathrm{min}$ using the range of $40-280{ }^{\circ} \mathrm{C}$ [23].

Microscopic Imaging Analysis (SEM). SEM is essentially a high magnification microscope, which uses a focussed scanned electron beam to produce images of the sample, both top down and with the no necessary sample preparation, cross-sections. Safeguard sample authenticity; safeguard credibility maintained by no coating requirement or other preparation prior to analysis. Prerequisite amount of polymer sample was putted in sample holder polymer window. It was operated at accelerated voltage $200 \mathrm{~V}$ to $30 \mathrm{kV}$. That can be used to highlight surface features or to limit or eliminate charging for samples [13-24]. It was enabled with both high and low vacuum mode was applied with $<2.0 \mathrm{~nm} @ 30 \mathrm{kV}$ high resolutions. It tends to emphasize the topographic nature of the specimen. The sample was analysed in QUANTA® 200 with EDS under 100, 500, 1000, 2000, 5000, $10000 \times$ magnifications.

\section{Result and Discussion}

\section{Screening and characterization of biopolymer from microbial source}

Primary screening of microbial source: Soil samples were collected near from Biotechnology department TKIET campus, Warananagar. It was found to be loamy and blackish in color. Isolation and purification of bacterial strains from soil sample was carried out. It were reported that 19 different viable colonies are produced on Nutrient agar plate with time span of 24 hours at $30^{\circ} \mathrm{C}$.

Screening for PHB producing bacterial strains: It was found that, out of 19 isolated colonies, 6 showed morphologically distinct characteristics were flooded with Sudan black-B solution (Table 1). The obtained cell mass from plates was then confirmed by Nile blue staining technique (Figure 1) and Volutin Granule staining (Figure 2) method. These both staining technique showed positive feedback for intra-granular PHB production $[13,14]$. Thus, these six isolates selected as prompt producer of PHB granules before that these isolates were verified by morphological tests like colony characterization. These purified isolate were coded before colony characterization.

Morphological characterization of microbial source: Colony characterization. The colony characters viz. Size, shape, Margin, Elevation, opacity and color were observed on agar medium (Table 1).

Table 1: Colony characterization of bacterial isolates.

\begin{tabular}{|c|c|c|c|c|c|c|}
\hline \multirow{2}{*}{ Isolate Code } & \multicolumn{5}{|c|}{ Colony Characteristics Parameters } \\
\cline { 2 - 7 } & Size & Shape & Margin & Elevation & Opacity & Colour \\
\hline SS1 & $>1 \mathrm{Mm}$ & Rod & Regular & Flat & Opaque & Pale yellow \\
\hline SS2 & $>1 \mathrm{Mm}$ & Circular & Regular & Convex & Opaque & Pale White \\
\hline SS3 & $1-2 \mathrm{Mm}$ & Rod & Rhizoidal & Flat & Opaque & Pale yellow \\
\hline SS4 & $>1 \mathrm{Mm}$ & Circular & Branched & Concave & Opaque & Pale yellow \\
\hline SS5 & $2-3 \mathrm{Mm}$ & Circular & Regular & Concave & Opaque & Off white \\
\hline SS6 & $>1 \mathrm{Mm}$ & Circular & Irregular & Convex & Opaque & Light pink \\
\hline \multicolumn{7}{|r|}{} \\
\end{tabular}


Table 2: Colony characterization of bacterial isolates.

\begin{tabular}{|c|c|c|}
\hline \multirow{2}{*}{ Isolate Code } & \multicolumn{2}{|c|}{$\begin{array}{c}\text { Dry Weight of Biomass Per 100ml Media } \\
\text { (Mg) }\end{array}$} \\
\cline { 2 - 3 } & Agar & Broth \\
\hline SS1 & 119 & 73 \\
\hline SS2 & 36 & 21 \\
\hline SS3 & 52 & 23 \\
\hline SS4 & 187 & 93 \\
\hline SS5 & 136 & 88 \\
\hline SS6 & 88 & 45 \\
\hline BM & 253 & 148 \\
\hline \multicolumn{2}{|c}{} \\
\hline
\end{tabular}

Harvesting of cellular biomass. Table 2 shows the dry weight of biomass per $100 \mathrm{ml}$ of nutrient media of the soil isolate and the standard organism Bacillus megaterium obtained from agar and broth medium. The all bacterial strains were capable of PHB synthesis. Bacteria accumulate maximum PHB during the stationary phase, in nutrient broth medium PHB yield become limited as compare to stationary phase due to nutrients availability becomes critical after some time period that reason was took into account and nutrient agar medium was selected for further studies. The lowest amounts of biomass showed by soil isolate SS2 that was $36 \mathrm{mg}$ and $21 \mathrm{mg}$ in nutrient agar and nutrient broth respectively $[15,16]$. Soil isolate SS5 showed $136 \mathrm{mg}$ and $88 \mathrm{mg}$ in nutrient agar and nutrient broth respectively. By considered other view of production standard PHB producer Bacillus megaterium yields $250 \mathrm{mg}$ of biomass which was greater than biomass yielded by other soil isolates organism hence that standard organism was selected for further production.

Production of biopolymer: Extraction of PHB. Nutrient agar was selected as the medium for maximum PHB yield. When all the bacterial isolates were grown on nutrient agar medium they produced various amount of PHB yield [17]. The isolate SS4 was yielded least amount of PHB yield $6 \% \mathrm{w} / \mathrm{w}$ dry cell weight while, at the same time other isolates SS1, SS2, SS3, SS5, SS6, yielded $12,9,11,15,14 \% \mathrm{w} / \mathrm{w}$ of dry cell weight respectively (Table 3). On other hand selected standard bacterial producer Bacillus megaterium yielded $18 \% \mathrm{w} / \mathrm{w}$ of dry cell weight.

Table 3: PHB Yield showed by all Microbes on nutrient agar medium

\begin{tabular}{|c|c|}
\hline Isolate & PHB Yield/ Dry Cell Weight $(\% \mathbf{W} / \mathbf{W})$ \\
\hline SS1 & 12 \\
\hline SS2 & 9 \\
\hline SS3 & 11 \\
\hline SS4 & 6 \\
\hline SS5 & 15 \\
\hline SS6 & 14 \\
\hline BM & 18 \\
\hline
\end{tabular}

\section{Selection of specific media composition for bacillus megaterium}

Method-A: In method- A the media composition was made by using commercially available carbon source Glucose with nitrogen source Peptone. The prime importance was gained by this method-A due to universal acceptance but high economy was spent on carbon and nitrogen sources, due to that reason method- B was took into account (Table 4).

Table 4: Specific media composition contained commercial Carbon and Nitrogen Source

\begin{tabular}{|c|c|c|c|}
\hline \multirow{2}{*}{ Ingredients } & \multicolumn{3}{|c|}{ Quantity (G/L) } \\
\cline { 2 - 4 } & BM1 & BM2 & BM3 \\
\hline Nutrient agar & 25 & 25 & 25 \\
\hline Glucose & 15 & 25 & 35 \\
\hline Peptone & 1 & 2 & 3 \\
\hline Beef extract & 5 & 5 & 5 \\
\hline $\begin{array}{c}\text { Potassium } \\
\text { dihydrogen } \\
\text { Phosphate }\end{array}$ & 2 & 2 & 2 \\
\hline $\begin{array}{c}\text { Disodium } \\
\text { hydrogen } \\
\text { Phosphate }\end{array}$ & 0.5 & 0.5 & 0.5 \\
\hline $\begin{array}{c}\text { Calcium } \\
\text { chloride }\end{array}$ & 0.5 & 0.5 & 0.5 \\
\hline $\begin{array}{c}\text { Magnesium } \\
\text { sulphate }\end{array}$ & 0.5 & 0.5 & 0.5 \\
\hline \begin{tabular}{c} 
Ferric Citrate \\
\hline Yeast
\end{tabular} & 0.5 & 0.5 & 0.5 \\
\hline $\begin{array}{c}\text { Trace element } \\
\text { solution }\end{array}$ & $3 \mathrm{~mL}$ & $3 \mathrm{~mL}$ & $3 \mathrm{~mL}$ \\
\hline
\end{tabular}

Method-B: In the method-B media composition contained Carbon and Nitrogen source Molasses and Ammonium chloride respectively both Sources was replaced by same quantities of carbon and nitrogen source followed by method-A. The carbon and nitrogen sources used in method-B are available cheaply as compare to sources used in Method-A (Table 5).

Table 5: Specific media composition contained cheaply available carbon and nitrogen source.

\begin{tabular}{|c|c|c|c|}
\hline \multirow{2}{*}{ Ingredients } & \multicolumn{3}{|c|}{ Quantity (G/L) } \\
\cline { 2 - 4 } & BM4 & BM5 & BM6 \\
\hline Nutrient agar & 25 & 25 & 25 \\
\hline Molasses & 15 & 25 & 35 \\
\hline $\begin{array}{c}\text { Ammonium } \\
\text { Chloride }\end{array}$ & 1 & 2 & 3 \\
\hline Beef extract & 5 & 5 & 5 \\
\hline $\begin{array}{c}\text { Potassium } \\
\text { dihydrogen } \\
\text { Phosphate }\end{array}$ & 2 & 2 & 2 \\
\hline $\begin{array}{c}\text { Disodium } \\
\text { hydrogen } \\
\text { Phosphate }\end{array}$ & 0.5 & 0.5 & 0.5 \\
\hline
\end{tabular}




\begin{tabular}{|c|c|c|c|}
\hline $\begin{array}{c}\text { Calcium } \\
\text { Chloride }\end{array}$ & 0.5 & 0.5 & 0.5 \\
\hline $\begin{array}{c}\text { Magnesium } \\
\text { sulphate }\end{array}$ & 0.5 & 0.5 & 0.5 \\
\hline Ferric Citrate & 0.5 & 0.5 & 0.5 \\
\hline Yeast & 10 & 10 & 10 \\
\hline $\begin{array}{c}\text { Trace element } \\
\text { solution }\end{array}$ & $3 \mathrm{~mL}$ & $3 \mathrm{~mL}$ & $3 \mathrm{~mL}$ \\
\hline
\end{tabular}

Table 6: PHB yield of Bacillus megaterium in BM specific Media

\begin{tabular}{|c|c|}
\hline Media & PHB Yield Dry Cell Weight $(\% \mathbf{W} / \mathbf{W})$ \\
\hline BM1 & 22 \\
\hline BM2 & 28 \\
\hline BM3 & 36 \\
\hline BM4 & 27 \\
\hline BM5 & 32 \\
\hline BM6 & 41 \\
\hline
\end{tabular}

The specific media for Bacillus megaterium required for optimum production of PHB were attained from literature. So yield of PHB in both methods was compared with each other (Table 4-6) it was found that standard Bacillus megaterium strains grown on BM specific medium they produced various extent of PHB yield. The least PHB yield showed by BM1 that was found to be $22 \% \mathrm{w} / \mathrm{w}$ dry cell weight which consisted $1.5 \%$ of glucose and $0.1 \%$ of peptone concentration. While maximum PHB yield showed by BM3 that was found to be $36 \% \mathrm{w} / \mathrm{w}$ dry cell weight at $3.5 \%$ glucose and $0.3 \%$ of peptone in media composition contained commercial carbon and nitrogen Source [17]. At same time PHB yield produced by media composition contained cheaply available carbon and nitrogen source. The yield of BM6 was found to be $27 \% \mathrm{w} / \mathrm{w}$ dry cell weight obtained from media containing $1.5 \%$ of molasses and $0.1 \%$ of ammonium chloride that was least yield, while $41 \% \mathrm{w} / \mathrm{w}$ dry cell weight of maximum yield obtained from BM6 that was found to be maximum yield as compare to yield obtained from all other media compositions. So BM6 was selected as potential PHB producer on large scale production.

\section{Characterization of PGB Biopolymer}

\section{Physiochemical characterization}

The PHB biopolymer samples were evaluated for its organoleptic properties [18]. The biopolymer are white in colour, Crystalline, stiff and brittle plastic in nature, as well as odourless and melting point is in the range of $175-177^{\circ} \mathrm{C}$.

\section{Solubility determination}

Table 7: Solvent system used in PHB solubility determination

\begin{tabular}{|c|c|}
\hline Solubility & Solvent \\
\hline \multirow{3}{*}{ Highly Soluble } & Chloroform \\
\cline { 2 - 2 } & Dichloromethane \\
\cline { 2 - 2 } & Acetic anhydride \\
\hline
\end{tabular}

\begin{tabular}{|c|c|}
\hline \multirow{4}{*}{ Poorly soluble } & 1N Sodium Hydroxide \\
\cline { 2 - 2 } & Acetic acid \\
\hline \multirow{4}{*}{ Practically insoluble } & Toluene \\
\cline { 2 - 2 } & Benzene \\
\cline { 2 - 2 } & Dioxane \\
\hline \multirow{4}{*}{} & Pyridine \\
\cline { 2 - 2 } & Water \\
\cline { 2 - 2 } & Methanol \\
\cline { 2 - 2 } & Ethanol \\
\cline { 2 - 2 } & Hexane \\
\hline
\end{tabular}

Solubility of PHB was confined or easy to soluble in different type of polar to non polar solvents [18] (Table 7).

\section{Rheological characterization}

Viscosity determination: The flow property of a system is expressed in terms of viscosity. Simply, viscosity is an index of resistance of liquid to flow. The higher the viscosity of liquid, greater is the resistance to flow. When solvent added in to polymer, the groups get easily hydrated in solution. When polymer molecules move, the hydrated solvent sheath moves. As a result, the size of polymer unit increases hence, increases the resistance the resistance to flow. The rheological characterisation of PHB was performed using Brookfield R/S-CPS+ Remoter.

Measurements were made by plate assembly. It was shown that viscosity of the PHB was measured as a function of temperature. Increasing the temperature leads to a change in the viscosity. As the temperature increases the system acquires thermal energy which facilitates the breaking of the cohesive forces. Increasing temperature range of the polymer substance that has impact on separation of molecule and reduces the intermolecular forces leads to reduced flow of the system $[19,20]$. Temperature Here the measurements were made at constant temperature $33.9^{\circ} \mathrm{C}$. The viscosity of PHB was affected by thermal instability due to this reason especially care was taken at the time of measurements; over all temperature of environ was maintained and measurement were carried out. Viscosity measurement of PHB shown in Figure 3 and the assignments were represented in Table 8.

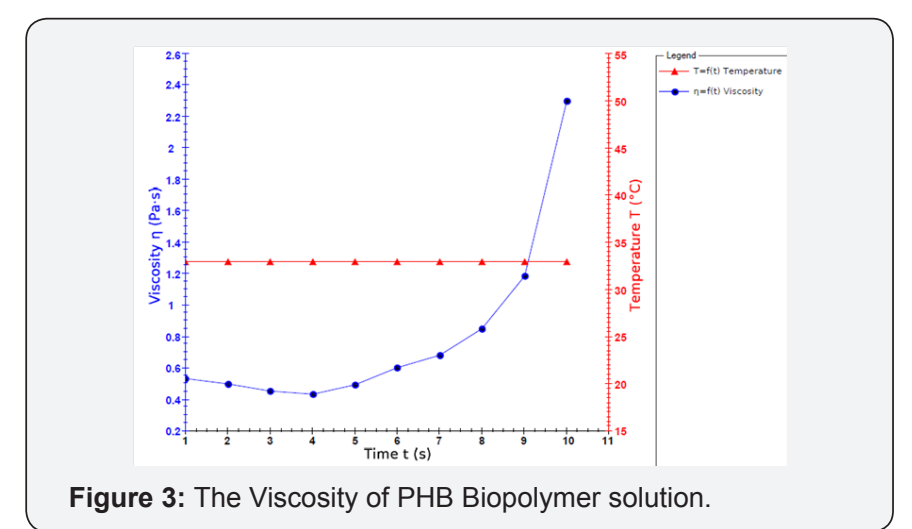


Table 8: Rheological behavior of PHB biopolymer solution.

\begin{tabular}{|l|l|l|l|}
\hline Parameter & Minimum & Maximum & Average \\
\hline Viscosity (Pas) & 0.4303 & 2.2936 & 0.7993 \\
\hline $\begin{array}{l}\text { Shear Stress } \\
\text { (Pa) }\end{array}$ & 22.9754 & 53.1547 & 32.2269 \\
\hline $\begin{array}{l}\text { S h e a r r } \\
\text { Rate(1/s) }\end{array}$ & 10.017 & 100.107 & 55.0323 \\
\hline
\end{tabular}

Spectral characterization: Ultraviolet (UV) spectrum. Ultraviolet spectroscopy is very useful and feasible analytical technique to assaying the variety of compounds. In this technique quantitative conversion of poly- $\beta$-hydroxybutyric acid to crotonic acid by heating in concentrated sulphuric acid and to found out scanning range of PHB (Law and Sleekly method). Sulphuric acid containing PHB solution was kept as test and read with sulphuric acid as blank in the range of wavelength from 200-400nm using UV spectrophotometer. The reported absorbance maxima ( $\lambda$ max) value for PHB is $235 \mathrm{~nm}$ [21,22]. Ultraviolet absorption maxima were recorded and $\lambda \max$ was found to be at $235.8 \mathrm{~nm}$. So, it was concluded that the obtained $\lambda$ max value much closer to report value that conforms the primary authentication of PHB polymer (Figure 4).

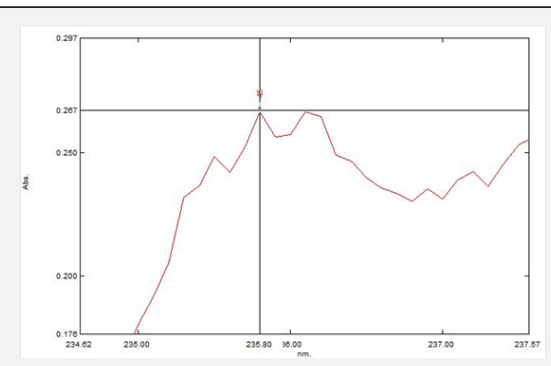

Figure 4: UV-Visible scanning spectra of PHB biopolymer solution.

\section{Fourier transforms infrared (FT-IR) spectroscopy}

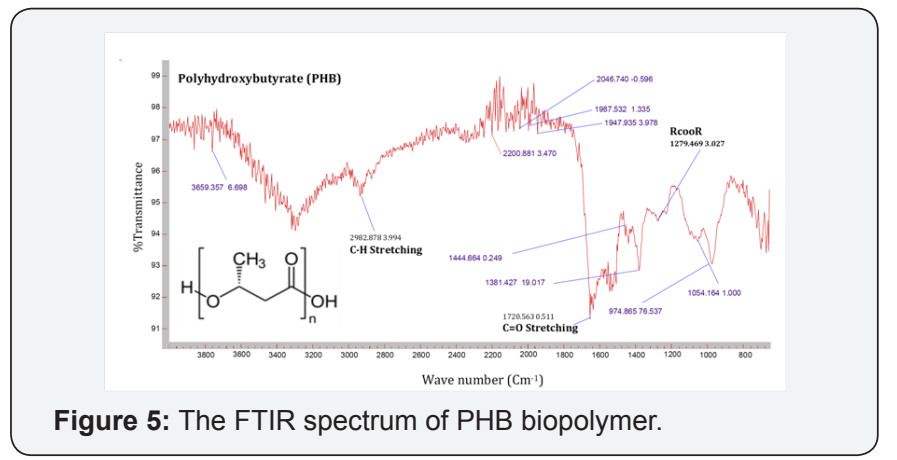

Table 9: EDS Multi-Component Quantification for Four PHB crystals. Polymer Crystal

\begin{tabular}{|c|c|c|c|c|c|c|c|}
\hline \multirow{6}{*}{1} & Element & $\mathrm{Wt} \%$ & At $\%$ & K-Ratio & $\mathrm{Z}$ & A & $\mathrm{F}$ \\
\hline & CK & 53.14 & 69.87 & 0.0763 & 1.0359 & 0.1386 & 1.0001 \\
\hline & $\mathrm{OK}$ & 11.13 & 11.13 & 0.0181 & 1.0186 & 0.1571 & 1.0004 \\
\hline & $\mathrm{NaK}$ & 12.14 & 8.34 & 0.0589 & 0.9535 & 0.5079 & 1.0014 \\
\hline & MgK & 0.89 & 0.58 & 0.0046 & 0.9775 & 0.5443 & 1.0024 \\
\hline & PK & 0.62 & 0.31 & 0.0052 & 0.9388 & 0.8822 & 1.0166 \\
\hline
\end{tabular}


Modern Applications of Bioequivalence \& Bioavailability

\begin{tabular}{|c|c|c|c|c|c|c|c|}
\hline & $\mathrm{ClK}$ & 21.94 & 9.77 & 0.196 & 0.9167 & 0.9748 & 1 \\
\hline & Total & 100 & 100 & & & & \\
\hline \multirow{9}{*}{$\begin{array}{c}\text { Polymer Crystal } \\
2\end{array}$} & Element & Wt \% & At $\%$ & K-Ratio & Z & A & $\mathrm{F}$ \\
\hline & CK & 19.53 & 28.44 & 0.0334 & 1.0377 & 0.1649 & 1.0005 \\
\hline & $\mathrm{OK}$ & 42.58 & 46.54 & 0.1234 & 1.0203 & 0.2839 & 1.0005 \\
\hline & $\mathrm{NaK}$ & 11.68 & 8.88 & 0.0485 & 0.9551 & 0.4338 & 1.0027 \\
\hline & $\mathrm{MgK}$ & 11.28 & 8.12 & 0.0534 & 0.9791 & 0.4824 & 1.0017 \\
\hline & PK & 9.64 & 5.44 & 0.0702 & 0.9406 & 0.7726 & 1.0024 \\
\hline & $\mathrm{Cl} \mathrm{K}$ & 4.65 & 2.29 & 0.0364 & 0.9186 & 0.8515 & 1.0005 \\
\hline & KK & 0.64 & 0.29 & 0.0055 & 0.9262 & 0.9196 & 1 \\
\hline & Total & 100 & 100 & & & & \\
\hline \multirow{9}{*}{$\begin{array}{c}\text { Polymer Crystal } \\
3\end{array}$} & Element & Wt $\%$ & At $\%$ & K-Ratio & Z & A & $\mathrm{F}$ \\
\hline & CK & 33.93 & 45.82 & 0.0643 & 1.0304 & 0.1838 & 1.0003 \\
\hline & OK & 36.02 & 36.52 & 0.0838 & 1.0132 & 0.2297 & 1.0003 \\
\hline & $\mathrm{NaK}$ & 5.66 & 3.99 & 0.0237 & 0.9484 & 0.4402 & 1.0026 \\
\hline & $\mathrm{MgK}$ & 8.67 & 5.79 & 0.046 & 0.9723 & 0.5442 & 1.0021 \\
\hline & PK & 10.92 & 5.72 & 0.0848 & 0.9336 & 0.8299 & 1.0024 \\
\hline & ClK & 4.13 & 1.89 & 0.0329 & 0.9115 & 0.8751 & 1.0006 \\
\hline & KK & 0.67 & 0.28 & 0.0058 & 0.9194 & 0.9354 & 1 \\
\hline & Total & 100 & 100 & & & & \\
\hline \multirow{8}{*}{$\begin{array}{c}\text { Polymer Crystal } \\
4\end{array}$} & Element & Wt \% & At $\%$ & K-Ratio & Z & A & $\mathrm{F}$ \\
\hline & C K & 24.18 & 41.86 & 0.021 & 1.0707 & 0.0809 & 1.0001 \\
\hline & $\mathrm{O} \mathrm{K}$ & 5.8 & 7.54 & 0.0099 & 1.0527 & 0.1627 & 1.0008 \\
\hline & Na K & 29.19 & 26.39 & 0.1589 & 0.9852 & 0.5514 & 1.002 \\
\hline & $\operatorname{Mg~K}$ & 0.84 & 0.72 & 0.0036 & 1.0099 & 0.4172 & 1.0033 \\
\hline & P K & 0.55 & 0.37 & 0.0044 & 0.9723 & 0.7904 & 1.0229 \\
\hline & $\mathrm{Cl} \mathrm{K}$ & 39.43 & 23.12 & 0.3449 & 0.9505 & 0.9202 & 1 \\
\hline & Total & 100 & 100 & & & & \\
\hline
\end{tabular}

EDS is the qualitative and quantitative method of analysis. In this technique the Scanning Electron Microscopic (SEM) imaging analysis was carried out to obtain the image. The refocused images with objects were highlighted by selecting individual peak ID. In which qualitative and quantitative analysis was carried out followed by the obtained peaks. These peaks represent the series of elements presents with quantitative figures of separated element in individual object. This technique offers the analytical measurement parameters such as detected element, At\%, Wt\%, K ratio, Z, A and F By observing the results values The results $\mathrm{PHB}$ crystals comprised varied concentration of $\mathrm{C}, \mathrm{O}, \mathrm{P}, \mathrm{K}, \mathrm{Cl}, \mathrm{Na}$ and $\mathrm{Mg}$ elements. The actual weight \% was calculated by multiplying the k-ratio by $100 \%$ and dividing by the product of the $\mathrm{Z}, \mathrm{A}$ and $\mathrm{F}$ factors. The obtained values for the entire individual particle were not same because the measured particles were not with same dimension. So obtained results are represents qualitative and quantitative analysis by showing separated peaks with varied concentration of elements [29]. The standard less results will always be normalized to $100 \%$. The peak for detected element concentration depicted in Figure 7-10. The obtained results for A t $\%$ and Wt\% for PHB crystal 1, 2, 3, and 4 from EDS are illustrated in Figure 11-14 respectively.

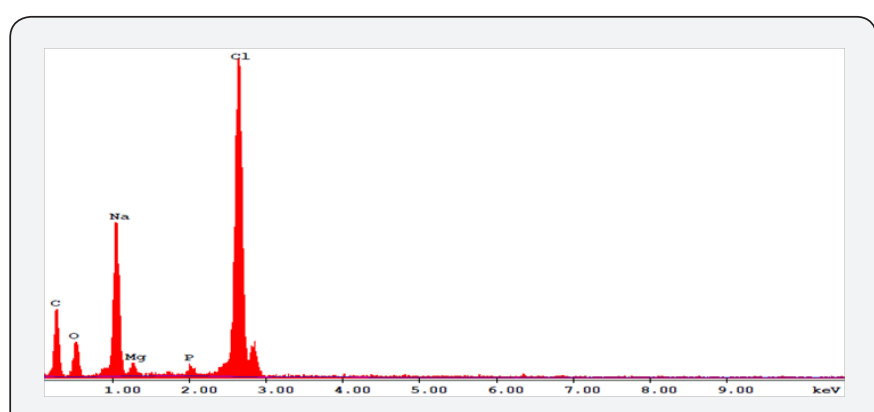

Figure 7: EDS spectrum of PHB crystal-1.

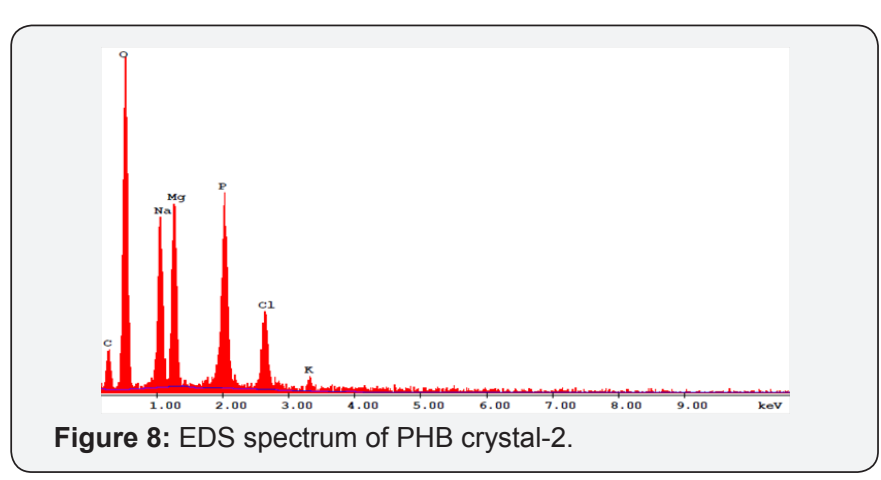




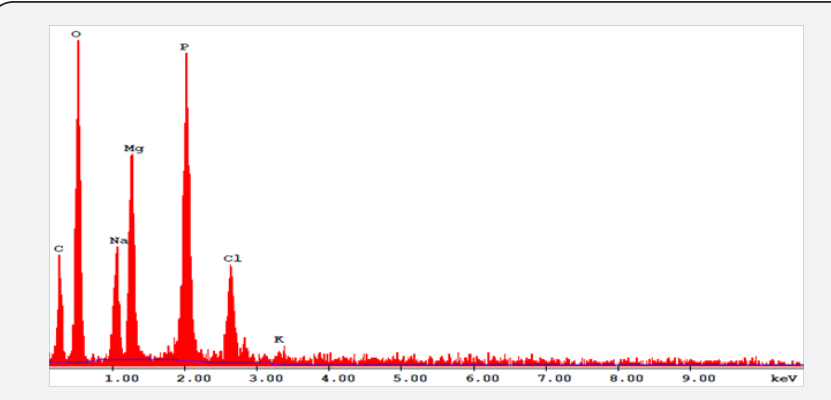

Figure 9: EDS spectrum of PHB crystal-3.

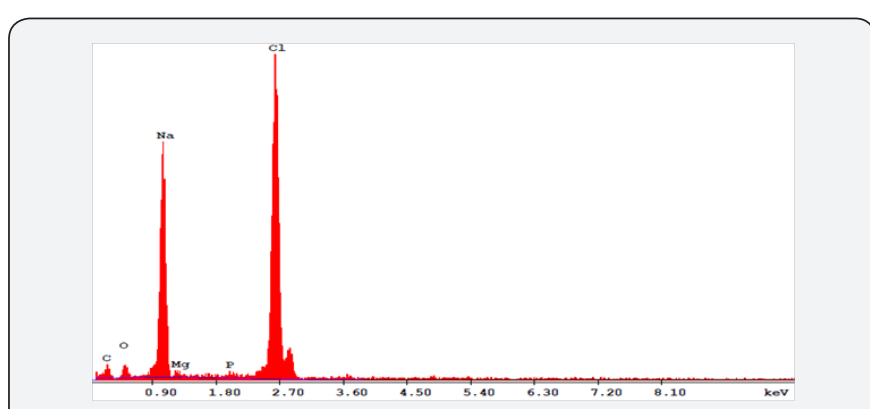

Figure 10: ED's spectrum of PHB crystal-4.

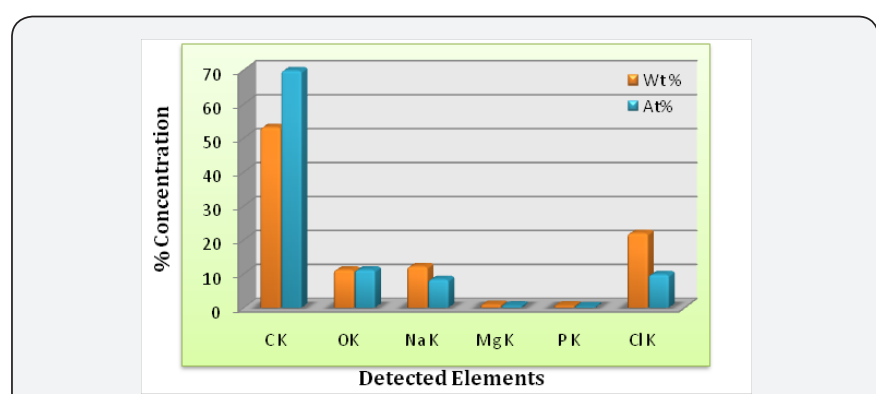

Figure 11: EDS Multi-component Analysis of Polymer crystal-1.

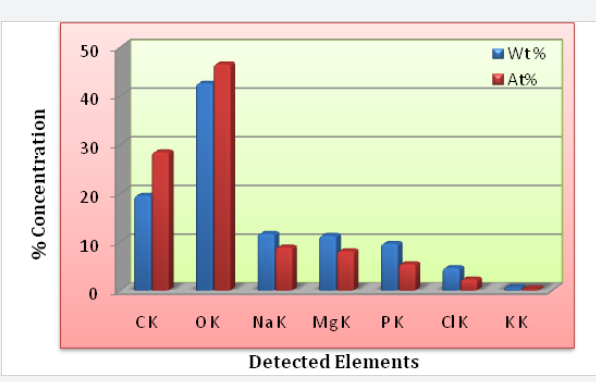

Figure 12: EDS Multi-component Analysis of Polymer crystal-2.

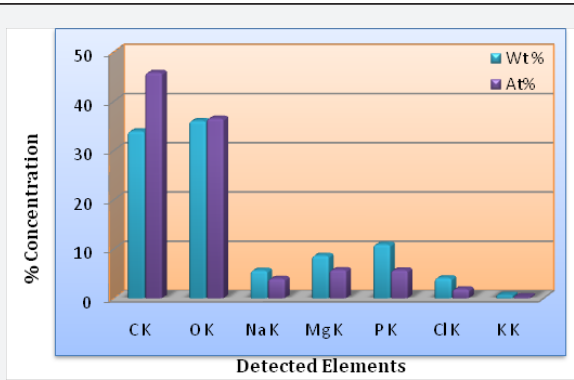

Figure 13: EDS Multi-component Analysis of Polymer crystal-3.

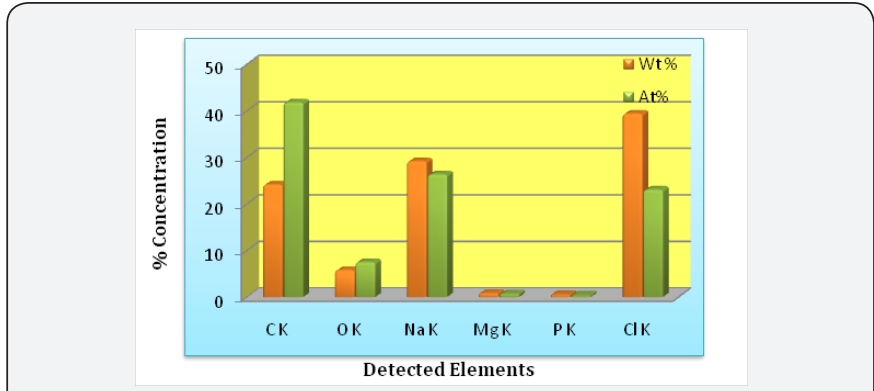

Figure 14: EDS Multi-component Analysis of Polymer crystal-4.

\section{Thermal characterization}

Differential scanning calorimetric: Differential scanning calorimetric provides a measurement of the rate, magnitude and temperature at which chemical or physical changes occur in a polymeric substance or system during heating or cooling. This PHB polymer was composed of single endothermic components with peak temperatures about $176.12{ }^{\circ} \mathrm{C}$. The formation of melting endothermic peak generally narrow can be due to the presence of crystalline structures [29]. PHB aroused sharp peak at $176.12{ }^{\circ} \mathrm{C}$ that analogous to the observed melting point temperature range $\left(175-177^{\circ} \mathrm{C}\right)$ of PHB by capillary method (Figure 15).

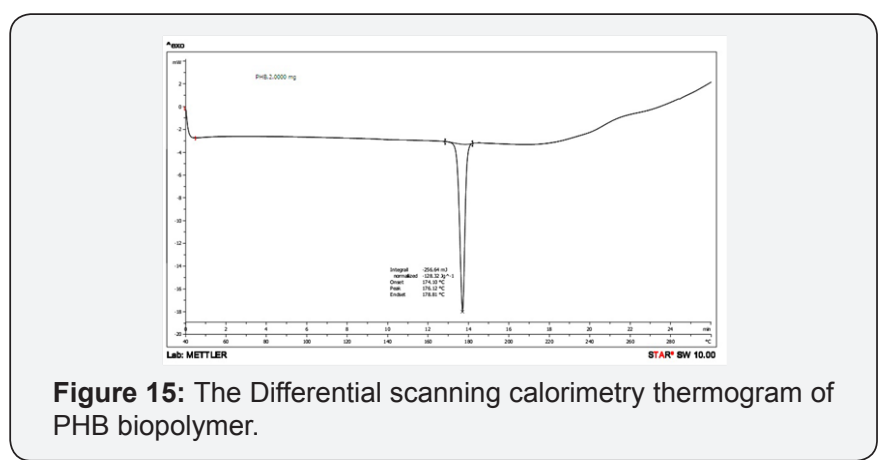

\section{Microscopic imaging analysis}

6.7.1.Scanning electron microscopy: The sample was analyzed in QUANTA 200 Scanning Electron Microscope under 100x, 500x, 1000x, 2000x, 5000x and 10000x magnification. SEM was illustrated with a high degree of magnification; highlighted surface features of screened PHB polymer. PHB enabled with crystalline, brittle surface morphology. PHB at 100x magnifications showed that spiky topographic arrangement. PHB magnified at 500x illustrated hard stone like surface structural arrangement and at 1000x magnification showed speckled particulate arrangement. PHB revealed irregular surface area with crest and trough at 2000x magnifications. Polymorphic granular matrix withheld at surface was shown in 5000x magnifications. PHB at $10000 \mathrm{x}$ showed that saturated dense globular micro particles at the surface. So it has revels that surface morphology of PHB distinctly discerns the polymer surface between the continuous spiky topographic arrangements of the major phase [29]. Materials have microscopically complex structure with a random distribution of dense globular pore 
sizes, due to its hard brittle nature found its prime applicability in packaging industry and pharmacy formulation practice. SEM micrographs at varied degree of magnifications are illustrated in Figure 16.

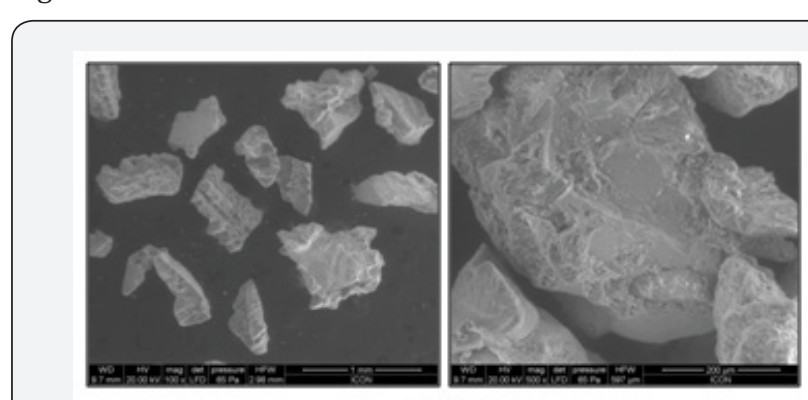

(a) (b)

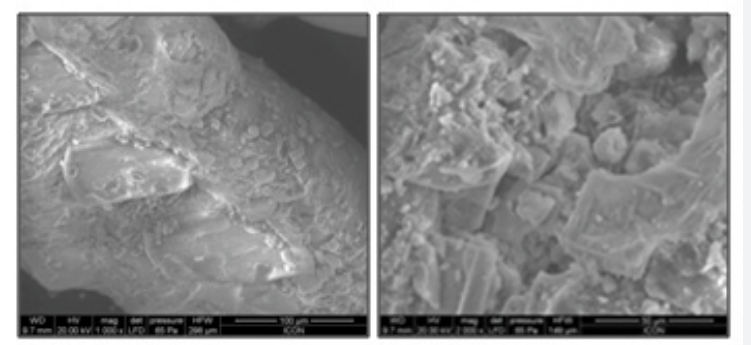

(c) (d)

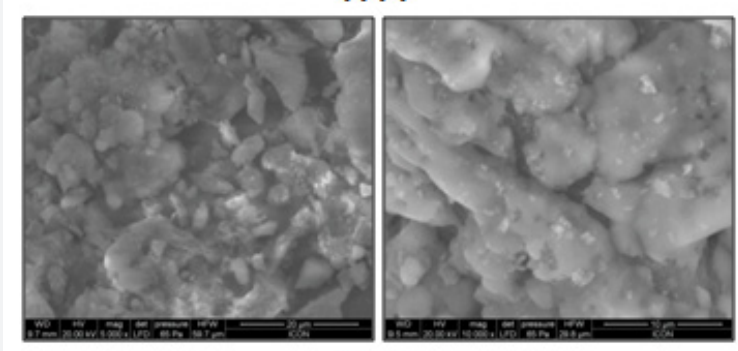

(e) (f)

Figure 16: Scanning Electron Microscopic Imaging Analysis of PHB magnified at (a) 100x, (b) 500x, (C) 1000x, (d) 2000x, (e) 5000 , (f) 10000x magnification.

\section{Conclusion}

The current study was based on screening of cost effective screening of Polyhydroxybutyrate (PHB) from bacterial genera biopolymer which would satisfy the growing demand of sustainable economic biopolymer production from bacterial genera. The cost effective polymer production with high yield and purity was the prime goal of study, so the soil isolates SS1, SS2, SS3, SS4, SS5, and SS6 were screened from soil samples. The solid state agar medium and nutrient broth were used as substrate for PHB production. Soil isolates had found to be ability to yield varying amount of PHB production, but polymer yielded by this isolates were lesser in quantity. Due to this reason Bacillus megaterium was used as prime PHB producer to yield maximum PHB production. But it was observed that polymer yield obtained from solid state substrate was higher as compare to the nutrient agar medium. The individual analysis viz; Physicochemical characterization Eg (Colour, odour, appearance melting point determination), Rheological characterization Eg
(Viscosity), Spectral characterization Eg (FTIR, UV spectrum, EDS), Thermal characterization Eg (DSC), Microscopic Imaging Analysis Eg (SEM) stands for giving assurance for its purity, conformity by explaining result value.

\section{Acknowledgement}

The authors gratefully acknowledge to Unique Biologicals, Kolhapur Dept. of Biotechnology, TKIET, Warananagar, Shivaji University and Kolhapur.

\section{References}

1. Lee S, Choi J, Wong H (1999) Recent advances in polyhydroxyalkanoate production by bacterial fermentation: mini review. Int J Biol Macromol 25(1-3): 31-36.

2. Findlay R, White D (1983) Polymeric betahydroxyalkanoates from environmental samples and Bacillus megaterium. Appl Environ Microbiol 45(1): 71-78.

3. Hirashi A, Khan S (1991) Application of Polyhydroxyalkanoate for dentrification in water and waste water treatment. Appl Microbiol Biotechnol 61(2): 103-109.

4. Samantaray S, Mallick N (2012) Production and characterization of poly- $\beta$-hydroxybutyrate (PHB) polymer from Aulosira fertilissima. Journal of Applied Phycology 24(4): 803-814.

5. Steinbuchel A, Schlegel H (1991) Physiology and molecular genetics of poly (beta-hydroxy-alkanoic acid) synthesis in Alacaligene eutrophus. Molecular Microbiology 5: 535-542.

6. Hauisman G, Leeuw O, Eggink B (1989) Synthesis of poly-3hydroxy alkanoates is a common feature of fluroscent pseudomonads. Appl Environ Microbiol 55(8): 1949-1954.

7. Wang F, Lee S (1997) Poly (3-hydroxybutyrates) Production with high polymer high productivity content by Fed-Batch culture of alcaligenes latus under nitrogen Limitation. Appl Environ Microbiol 63(9): 37033706.

8. Jirage AS, Baravkar VS, Kate VK, Payghan SA, Disouza JI, et al. (2013) Poly- $\beta$-Hydroxybutyrate: Intriguing Biopolymer in Biomedical Applications and Pharma Formulation Trends. Int J Pharma Bio Arch 6: $1107-1118$

9. Payghan SA, Kate VK, Khavane K, Purohit SS (2010) Pharmaceutical Solid Polymorphism: Approach in Regulatory Consideration. Journal of Global Pharma Technology 1(2): 45-53.

10. Toppo E, Payghan SA, Bhargava S (2007) Role of bioprofiling and chemo profiling for herbal drugs: A Review. International Journal of Green Pharmacy 1(2): 7-10.

11. Verlinden R, Hill D, Kenward M, Williams C, Radecka I, et al. (2007) Bacterial synthesis of biodegradable Polyhydroxyalkanoates. J Appl Microbiol 102(6): 1437-1449.

12. Omar S, Rayer S, Equaab A, Viss R, Steinbuchel A, et al. (2001) Optimziation of cell growth and poly- $\beta$-hydroxybutyrate accumulation on date syrup by Bacillus megaterium strain. Biotechnology Letters 23: 1119-11123.

13. Hartman T (1940) The use of Sudan Black B as a bacterial fat stain. Stain Technology 15(1): 23-28.

14. Stokes K, Kimbrough C (1942) Studies of the common aerobic sporeforming Bacilli staining for fat with Sudan Black B- stain. Journal of Bacteriology 43(6): 717-724.

15. Yu J, Chen L (2006) Cost-effective recovery and purification of polyhydroxyalkanoates by selective dissolution of cell mass. Biotechnol Prog 22(2): 547-553. 
16. Kunasundari B, Sudesh K (2011) Isolation and recovery of microbial polyhydroxyalkanoates. Express Polymer Letters 5(7): 620-634.

17. Pandit P, Ghat B, Kulkarni C, Mungi D, Patel T, et al. (2011) PHB production using novel agro-industrial sources from different bacillus species. International Journal of Pharma and Bio Sciences 2(3).

18. Payghan SA, Cheke PA, Jirage AS (2014) Bioprofiling and chemoprofiling of stevia rebaudiana potential natural sweetener as an excipient portfolio. Inventi Impact: Novel Excipients (4): 149-162.

19. Jadhav CM, Kate V, Payghan SA (2015) Investigation of effect of non-ionic surfactant on preparation of griseofulvin non-aqueous nanoemulsion. Journal of Nanostructure in Chemistry (Springerlink. com) 5(1): 107-113.

20. Wanga B, Sharma SRR, Olsonb JW, Khan SA (2013) Production of Polyhydroxybutyrate (PHB) by Alcaligenes latus using sugarbeet juice. Industrial Crops and Products 43: 802-811.

21. Serap Y, Rouhollah K, Gozde U, Immihan CG, Zahide DM (2015) Synthesis and characterization of polyhydroxybutyrate coated magnetic nanoparticles: toxicity analyses on different cell lines. Synthesis and Reactivity in Inorganic Metal-Organic and Nano-Metal Chemistry 45(5): 700-708.

22. Irsath H, Santhosh S, Hemalatha V, Vikramathithan M, Dhanasekar R, et al. (2015) Production and optimization of polyhydroxybutyrate using bacillus subtilis BP1 isolated from sewage sample. Int J Pure App Biosci 3(1): 158-166.
23. Ghulam K, Ahmad P, Bohari B, Nor HA, Mat YAM, et al. (2105) Production of polyhydroxybutyrate in oil palm (Elaeis guineensis Jacq.) mediated by microprojectile bombardment of PHB biosynthesis genes into embryogenic calli. Front Plant Sci 6: 598.

24. Law J, Slepecky R (1961) Assay of poly- $\beta$-hydroxybutyric acid. J Bacteriol 82: 33-36.

25. Hinde SM, Payghan SA, D'souza JI (2014) Physiochemical assessment of pharmaceutical salt Forms: a quality attribute. International Research Journal for Inventions in Pharmaceutical Sciences 2(2): 46-53.

26. Chaijamrus S, Udpuay N (2008) Production and characterization of polyhydroxybutyrate from molasses and corn steep liquor produced by bacillus megaterium atcc 6748. Agricultural Engineering International (10): 1-9.

27. Kate VK, Payghan SA (2013) Physicochemical evaluation of mannitol based mucoadhesive fast disintegrating tablet for rapid absorption of piroxicam. Inventi Rapid Pharm Tech 2013(3): 1-15.

28. Karahaliloğlu Z, Ercan B, Taylor EN, Chung S, Denkbaș EB, et al. (2015) Antibacterial nanostructured polyhydroxybutyrate membranes for guided bone regeneration. J Biomed Nanotechnol 11(12): 2253-2263.

29. Cavaillé L, Albuquerque M, Grousseau E, Lepeuple AS, Uribelarrea JL, et al. (2015) Understanding of polyhydroxybutyrate production under carbon and phosphorus-limited growth conditions in non-axenic continuous culture. Bioresource Technology 201: 65-73.

Your next submission with Juniper Publishers
will reach you the below assets
- Quality Editorial service
- Swift Peer Review
- Reprints availability
- E-prints Service
- Manuscript Podcast for convenient understanding
- Global attainment for your research
- Manuscript accessibility in different formats
( Pdf, E-pub, Full Text, Audio)
- Unceasing customer service
Track the below URL for one-step submission
https://juniperpublishers.com/online-submission.php

